\title{
Ueber Pasta gummosa;
}

\author{
von \\ Dr. Geiseler, \\ Apotheker zu Königsberg in der Neumark.
}

Die von mir im Archiv (I. R. XXIX. 60.) früher gegebene Vorschrift zur Bereitung der Pasta gummosa, nach welcher einer erkalteten Auflösung von 16 Unzen Mimosengummi und eben so viel Zucker in 50 Unzen Wasser das zu Schaum geschlagene Eiweiss zugesetzt, und das Ganze bis zur gehörigen Consistenz über gelindem Feuer oder im Wasserdampfbade abgedampft wird, ist, wie mir bekannt geworden, von Vielen benutzt. Diess veranlasst mich, in Bezug auf das Zerschneiden der Pasta, welches ich im halbtrockenen Zustande derselben vorzunehmen rieth, jetzt noch zu bemerken, dass das Zertheilen der Pasta in kleinere Stücke sich auch sehr gut nach dem vollständigen Austrocknen derselben, wie schon Dulk in seinem Commentar zur Preussischen Pharmakopöe angegeben, mittelst einer feinen Säge bewirken, ja noch besser ausführen lässt. Die in Papierkapseln ausgegossene oder vielmehr darin durch Ausbreiten vertheilte Pasta trocknet man am besten auf Haarsieben oder mit Leinwand uberspannten Rahmen bei einer Temperatur, die $+63^{\circ} \mathrm{R}$. nicht uberschreitet. Das Haartuch des Siebes oder die über einen Rahmen gespannte Leinwand darf nicht durch Holz oder andere feste Körper auf den Stellen unterstiitzt werden, auf welchen sich die Papierkapseln mit der Pasta befinden, da sonst die leicht durch blosses Abziehen zu bewirkende Trennung der Pasta von dem Papier sehr erschwert wird. Ist die Temperatur beim Trocknen höher, als oben angegeben, so wird die Pasta leicht gelb. Ihre Lockerheit wird dadurch sehr befördert, dass sie, sobald sie in Papierkapseln gebracht ist, auch sogleich der Wärme ausgesetzt wird, in welcher sie vollkommen ausgetrocknet werden soll; dies Austrocknen geschieht denn auch vollständig innerhalb 12 bis 16 Stunden. 
$28 \quad$ Verunreinigung des salpetersauren Silberoxyds.

Von einigen Aerzten wird zuweilen eine Auflösung der Pasta gummosa in Wasser verschrieben. Ist die Pasta beim Abdampfen und Trocknen einer zu hohen Temperatur ausgesetzt gewesen, so erhält man eine unvollständige. wenigstens sehr ungleichartige Lösung, wogegen die im Wasserdampfbade und bei gelinder Wärme getrocknete Pasta eine bessere Mischung darstellt. Man muss indes sen die Auflösung der Pasta in Wasser nicht durch Wärme unterstiutzen, da diese ein vollständiges Gerinnen des Eiweisses und die Bildung von grösseren und kleineren Klössen beginstigt. Unter allen Umständen erscheint es am zweckmässigsten, die trockne Pasta zu pulvern und das Pulver mit dem kalten Menstruum in derselben Weise zu mischen, wie man Pulvis G. arabici in einem Mörser in kaltem Wasser auflöst. Will man das Pulver der Pasta vorräthig halten, so muss man es in einem gut verstöpselten Glase aufbewahren, da es begierig die Feuchtigkeit anzieht.

Ueber die äussere Beschaffenheit der Pasta gummosa spricht sich die Preussische Pharmakopöe dahin aus, dass sie nicht zähe (haud tenax) sein soll; es scheint aber, als wenn der allgemein gebräuchliche deutsche Name „Lederzucker " darauf hindeute, dass sie durch Anziehung von Feuchtigkeil etwas zäher geworden sein muss, da ganz trockne Pasta auch nicht im Entferntesten zu der Bemer kung "Lederzucker "Veranlassung geben kann.

\section{Verumreinigung des salpetersauren Silberoxyds mit schwefelsaurem Silberoxyd.}

Der Höllenstcin gehört nach meinem Dafürhalten zu denjenigen chemischen Präparaten, deren Darstellung man am besten den chemischen Fabriken überlässt Man erhält denselben in der That jetzt von so vollkommener Weisse und Reinheit aus den Fabriken, dass alle Anforderungen vollkommen befriedigt werden. Noch niemals zuvor habe ich irgend einen Fchler an diesem Producte 